\title{
Género, violencia sexual y delito en Carne de perra de Fátima Sime
}

Gender, sexual violence, and crime in Carne de perra by Fátima Sime

Gênero, violência sexual e delito em Carne de perra de Fátima Sime

\section{Bernardita Llanos M.}

BROOKLYN COLLEGE, CUNY, ESTADOS UNIDOS

Professor y Chair en el Department of Modern Languages and Literatures

en Brooklyn College, CUNY. PhD, University of Minessota. Su

trabajo reciente se concentra en las producciones documentales

y testimoniales que indagan acerca de la memoria traumática de

mujeres latinoamericanas que han padecido violencia política. Es

autora de Passionate Subjects/Split Subjects in Twentieth-Century

Literature in Chile: Brunet, Bombal, and Eltit (Bucknell UP, 2009), y coeditora de Chile de memoria: a 40 años del golpe (U

Fernando Pessoa, 2016), entre otros. Actualmente, trabaja en

el manuscrito de su próximo libro sobre memoria y violencia

político-sexual. Correo electrónico: bllanos@brooklyn.cuny.edu

Artículo de reflexión.

Documento accesible en línea desde la siguiente dirección: http://revistas.javeriana.edu.co

doi:10.11144/Javeriana.cl21-42.gvsd 


\section{Resumen}

Este artículo traza una lectura de la novela Carne de perra (2009), de la chilena Fátima Sime. La prosa de Sime indaga sobre los escenarios de justicia y reparación (im)posibles a los que se enfrenta una mujer víctima del repertorio de torturas que la DINA deparaba a las disidentes (abuso sexual). A partir del texto de Sime, el artículo elabora una crítica, de alcance más amplio, a la ideología patriarcal y a las formas en que esta subyace a la democracia posdictatorial. Carne de perra — se concluye aquí- es, tal vez, el relato más osado de la literatura chilena reciente por cuanto pone en escena los pliegues de un sistema judicial cuyos ojos permanecen vendados ante el cuerpo de las mujeres.

Palabras clave: derechos humanos; mujeres-víctimasdictadura-chilena; tortura; Fátima Sime; contrato social

\section{Abstract}

This article outlines a reading of the novel Carne de perra (2009), by the Chilean Fátima Sime. Sime's prose explores the (im)possible scenarios of justice and reparation faced by a woman victim of the torture repertoire that the DINA had in store for dissident women (sexual abuse). From the text of Sime, this article creates a critique, with a broader scope, to the patriarchal ideology and the ways in which it underlies postdictatorial democracy. Carne de perra, as we conclude here, is perhaps the most daring tale of recent Chilean literature, as it brings to the spotlight the folds of a judicial system whose eyes remain blindfolded before the bodies of women.

Keywords: human rights; womenvictims-Chilean dictatorship; torture; Fátima Sime; social contract

\section{Resumo}

Este artigo traça uma leitura do romance Carne de perra (2009), da chilena Fátima Sime. A prosa de Sime indaga sobre os cenários de justiça e reparação (im) possíveis enfrentados por uma mulher vítima do repertório de torturas que a DINA realizou às mulheres dissidentes (abuso sexual). A partir do texto de Sime, o artigo elabora uma crítica, de alcance mais amplo, à ideologia patriarcal e as formas em que esta subjaze à democracia pós-ditatorial. Carne de perra -conclui-se aqui-é, talvez, o relato mais ousado da literatura chilena recente por quanto põe em cena os dobros de um sistema judicial cujos olhos permanecem vendados diante do corpo das mulheres.

Palavras-chave: direitos humanos; mulheres-vitimasditadura-chilena; tortura; Fátima Sime; contrato social

RECIBIDO: 15 DE JULIO DE 2016. ACEPTADO: 22 DE OCTUBRE DE 2016. DISPONIBLE EN LínEA: 29 DE DICIEMBRE DE 2017

\section{Cómo citar este artículo:}

Llanos M., Bernardita. "Género, violencia sexual y delito en Carne de perra de Fátima Sime".

Cuadernos de Literatura 21.42 (2017): 219-237. https://doi.org/10.11144/Javeriana.cl21-42.gvsd 
LOS DERECHOS HUMANOS han constituido uno de los discursos y luchas más relevantes para la consecución de la democracia y la justicia en Chile. Las organizaciones de derechos humanos, de familiares de detenidos desaparecidos y de fusilados políticos, como es sabido, han sostenido una prolongada y valiente batalla por el derecho a la memoria, la verdad y la justicia, una de las demandas más urgentes y fundamentales para la política, la cultura y la jurisprudencia después de cuarenta años del golpe militar de 1973. Hoy, este activismo incluye la denuncia y condena de los delitos sexuales y de género cometidos durante la dictadura contra mujeres militantes detenidas ilegalmente y cuyos derechos humanos fueron cruentamente violados. Como se sabe, desde el comienzo de la democracia en 1990, las concesiones a los militares definieron una justicia "en la medida de lo posible", como afirmó el presidente Patricio Aylwin en su momento. ${ }^{1}$

Más de dos décadas después de conseguida la democracia, predomina un pacto de silencio institucionalizado sobre los archivos de las violaciones de los derechos humanos, dispuesto por un periodo de cincuenta años por el presidente Ricardo Lagos en el 2014. A pesar de los avances institucionales y de los diversos informes, Rettig, Valech I y II, producto de las Comisiones de Verdad y Reconciliación, así como de la creación de un Instituto de Derechos Humanos y de una serie de juicios y procesamientos a miembros de los servicios de inteligencia de la dictadura, el silencio de los militares y la inaccesibilidad a la información sobre los crímenes y sus autores, contenida en los informes, limitan seriamente el avance en materia de justicia y coloca a Chile muy por detrás de los logros en el campo del derecho internacional a nivel global. Junto a las limitaciones de acceso y conocimiento público de los archivos, en Chile, la violación sexual y los abusos sexuales como un sistema de tortura aplicado específicamente a las mujeres aún sigue siendo casi invisible como categoría analítica y jurídica, tal como han afirmado abogadas, cientistas políticas y activistas feministas al referirse a la violencia política contra las mujeres. De hecho, en el marco de las teorizaciones sobre el derecho y a raíz de los cambios del derecho internacional, se requiere de un estatuto de género aparte, dentro de las violaciones de los derechos humanos como delitos de lesa humanidad, que examine y evalúe específicamente las formas en que la tortura cobra un carácter sexual y de género. Tema este pendiente y de gran relevancia en el contexto chileno, donde la violación sexual

1 Frase pronunciada por Aylwin durante una alocución que tuvo lugar en el Estadio Nacional de Santiago de Chile el día 12 de marzo de 1990. 
y las aberraciones sexuales tenían como fin la destrucción de los opositores políticos de la dictadura, al convertir el cuerpo de las mujeres prisioneras en medio y signo de la destrucción genocida contra la izquierda. Como subraya Carolina Carrera en su artículo "Secrets Revealed: Women Victims of Sexual Violence as Torture During Chile's Era of Political Repression, 1973-199o", la violencia sexual y de género fue practicada por todas las ramas de las Fuerzas Armadas como un método de tortura contra las mujeres, que se sistematizó e institucionalizó en todos los centros de detención, campos de concentración, estadios y prisiones clandestinas como Villa Grimaldi, el Cuartel Ollague, el estacionamiento subterráneo de la Plaza de la Constitución, el Estadio Nacional, Tres Álamos, Cuatro Álamos, La Venda Sexy, Londres 38, la Academia de Guerra de la Fuerza Aérea, el Cuartel Borgoño, la base aérea El Bosque y el Regimiento de Buin; y en las provincias, en el centro de detención Tejas Verdes, el buque Esmeralda y la Isla Quiriquina. Todas estas cárceles clandestinas aparecen frecuentemente mencionadas por las mujeres sobrevivientes de la región metropolitana entrevistadas por Carrera. El secreto que revelan las entrevistas es que mujeres de todas las edades, clase social, etnia y estatus fueron blanco de la violencia sexual, incluso las embarazadas. Las mujeres campesinas, profesionales, militantes, universitarias, trabajadoras y dueñas de casas que resultaron detenidas fueron víctimas de la violencia y convertidas en una representación más de "la prostituta traidora". Según el estudio de Carrera, las mujeres que fueron víctimas de tortura sexual pertenecían a dos grupos: (a) eran militantes de izquierda o actuaban en política; (b) estabas relacionadas con un hombre activo en política que era considerado enemigo del régimen militar. El castigo y la tortura para este segundo grupo, según Carrera, era mayor, pues las prisioneras terminaban convertidas en "posesiones" de enemigos a los que había que deshonrar, humillando y violando a sus hijas, esposas, compañeras o hermanas.

Los textos testimoniales, la literatura y el cine han sido centrales en la visibilización de las violaciones a los derechos humanos y, en especial, de los abusos sexuales y de género que sufrieron las prisioneras políticas durante la dictadura de Pinochet. Sin embargo, estos delitos siguen impunes a nivel jurídico nacional, precisamente por la ausencia de una perspectiva de género para interpretarlos cultural y legalmente, falencia que también han observado historiadoras y abogadas feministas al referirse a los informes de las Comisiones Rettig y Valech I y II - entre ellas, Hillary Hiner, Lorena Fríes, Victoria Hurtado y Ximena Zabala-. En ninguno de estos informes existe la categoría de violencia sexual ni la de violación sexual como delitos de lesa humanidad, 
específicamente cometidos contra las mujeres como grupo, para ser reeducadas o destruidas identitaria y corporalmente al ser consideradas enemigas del Estado. En este sentido, la jurisprudencia chilena está muy por detrás de las diversas legislaciones de la Corte Penal Internacional, de los estatutos del Consejo de Seguridad de Naciones Unidas después de la guerra en la exYugoslavia y de la reglamentación de las comisiones sobre los crímenes de genocidio que incluyen los arriba mencionados y los que se articularon a raíz del genocidio de Ruanda contra las mujeres tutsi y las mujeres mayas en Guatemala. Tal como señala Miranda Cassino, la figura del genocidio contribuye a la reflexión sobre las estrategias de la violencia ejercida sobre los cuerpos de las víctimas, dado que muestra las "formas particulares de violencia, género-estructuradas", como también "la imbricación entre violencia y formas sexualizadas de agresión" (286).

Lorena Fríes, Victoria Hurtado y Ximena Zabala afirman que para el caso chileno "no ha habido capacidad de relacionar la violencia [sufrida por la mujer] con la violencia política, ni específicamente con la violencia sexual como forma de tortura sufrida por las mujeres durante la represión" ni en el movimiento feminista, ni en las organizaciones de derechos humanos ni en la sociedad civil (129). Este vacío teórico y práctico sigue teniendo consecuencias serias para el avance de la justicia y la democracia en Chile.

El uso del sexo con el fin de destruir a un grupo, como apunta la jurista Catharine MacKinnon, implica que la violación sexual está controlada y que los hombres la realizan porque se les ordena o motiva a ello o se les permite sistemáticamente violar por ser miembros de un grupo específico - que se considera a sí mismo superior - dentro de un país, de una raza o una religión. De este modo, la violación sexual tiene el propósito no solo de hacer daño o de simplemente tener sexo, sino de destruir a un grupo previamente designado. Más aún, MacKinnon advierte que el genocidio es una forma extrema de desigualdad y de discriminación perpetrada a través de la violencia sistemática que a veces es liderada por el Estado u otras fuerzas militares no oficiales (328-329). Lo distintivo de este fenómeno es que el trabajo genocida se realiza a través de asaltos sexuales para destruir al otro por su pertenencia a un grupo particular (329-330).

$* * *$

La novela Carne de perra (Santiago: Lom, 2009) de Fátima Sime relata la historia de una sobreviviente de tortura y secuestro durante la dictadura, cuya vida queda 
escindida entre el pasado como prisionera política y el presente en una ciudad que vive como si nada hubiera ocurrido. María Rosa, la protagonista, trabaja como enfermera en la Posta Central y su memoria del pasado como presa política - detenida por ser novia de un militante-, la acecha con escenas que reviven su victimización, tortura y abusos sexuales a manos de Emilio Frank, alias el Príncipe, un agente de la policía secreta de la dictadura. La violación del derecho a la integridad personal y a la libertad mediante la tortura sexual como delito de lesa humanidad cometido durante el terrorismo de estado, representa un tema pendiente y fundamental en la democracia chilena que la novela explora hasta sus últimas consecuencias, al enfrentar a la víctima cara a cara con el perpetrador años después de su liberación. ${ }^{2}$ La novela indaga sobre la justicia y la reparación para una mujer víctima del abuso sexual como tortura, y lo hace desde la perspectiva de la sobreviviente. En la textualización de un punto de vista de género radica el aporte central de Carne de perra, que representa las formas extremas de violencia contra la mujer durante la dictadura desde la posición y mirada de la sobrevivencia. En este sentido, el relato se diferencia de otras novelas como El desierto (2005) de Carlos Franz y La vida doble (2010) de Arturo Fontaine, las cuales mantienen una perspectiva de género masculina en la representación de la experiencia del abuso sexual como tortura e intimidación sufrida por sus protagonistas durante el terrorismo de estado en Chile.

Carne de perra, además de tematizar el trauma producto de la tortura, el encarcelamiento ilegal y la esclavitud sexual, se inscribe dentro del discurso narrativo inaugurado por Marta Brunet con su novela María Nadie (1957), cuya protagonista, al igual que María Rosa en Carne de perra, proviene de un pueblo de provincia (Limache), es de clase media (tiene un padre taxista y sindicalista), vive en la ciudad de Santiago sola y por sus propios medios, gracias a su trabajo en la Posta Central. Del hostigamiento social, condena moral y la persecución sufridas por María Nadie en la década del cincuenta, somos testigos en el 2009, pues se nos muestra una de las formas de violencia sexual y de género más brutales cometidas contra la mujer durante el régimen dictatorial a través del secuestro, el encarcelamiento y la esclavización sexual de la protagonista. La novela denuncia la violación sistemática y planificada

2 Este encuentro y la memoria del pasado violento recuerdan el texto dramático La muerte y la doncella (1991) de Ariel Dorfman, después llevado al cine en la película Death and the Maiden (dir. Roman Polanski, 1994), donde la protagonista también se vuelve a encontrar con su torturador en un Chile democrático e indiferente a su experiencia traumática para la cual no ha habido justicia. 
de los derechos humanos y la violación sexual como tortura sistemática en la figura de su protagonista, María Rosa, junto a las secuelas físicas y psicológicas de la experiencia de aflicción y degradación vividas que persisten después de su liberación, exilio en Suecia y retorno a Chile. Cristián Montes subraya que "la tortura intenta producir la pérdida de control sobre las funciones subjetivas, lo cual funciona también como signo de la muerte subjetiva" de la protagonista. En este contexto la culpabilidad o inocencia de la víctima no tienen importancia, porque se trata de que el torturador consiga imponer su poder sobre ella y no de extraer información como confirma la novela.

Por otra parte, y a contra pelo de la negligencia de la ley y la indiferencia institucional con respecto a estos abusos, buena parte de la literatura chilena se ha caracterizado por su interés social y gran atención a la marginalización (de clase, género, etnia o sexualidad) y a la denuncia del abuso de poder como lo muestran en sus obras escritores tales como Bombal, Brunet, Donoso, Droguett, Eltit y Lemebel, entre otros a través del siglo XX y XXI. En sus textos se identifica y reconoce el abuso de poder en particular hacia las mujeres, quienes como grupo han ocupado una posición subordinada al interior de la jerarquía de clase y la racialización junto a otros grupos tradicionalmente marginados como los mapuches, los homosexuales y otras minorías sexuales. La representación de la violencia está, pues, íntimamente ligada con las construcciones de códigos sociales que se articulan y definen de manera jerárquica. De hecho, la crítica Mary Louise Pratt propone que la violencia entre los hombres en América Latina se entiende como una ruptura del contrato social, mientras que la violencia de un hombre contra una mujer se considera como "afirmación o actuación del contrato social, o como evidencia de su poder excesivo" (Pratt 93). Como argumenta Carol Pateman en su libro The Sexual Contract (1988) y con quien concuerda Pratt, el contrato social tiene un carácter fraternal masculino que se fundamenta en el acuerdo sexual en un régimen de género estructurado sobre el dominio masculino y la subordinación femenina reactualizada y reproducida a través de toda la sociedad.

En este contexto contractual la literatura vendría a representar la desintegración de los códigos sociales entre los hombres y las mujeres, en el momento en que se da un conflicto político que se percibe como una amenaza a la identidad nacional (Mendoza 1). En el caso de Chile el golpe de estado y la dictadura son expresiones cruentas de la violencia política y de la violación de los derechos humanos con la garantía de impunidad para los agentes del estado, quienes quedaron libres para cometer todo tipo de abusos 
y aberraciones sexuales dentro del plan general de eliminar a la oposición política. Es esta misma impunidad la que permite que no solo se realicen los crímenes, sino que se oculten, con el agravante de la ausencia de escucha y la casi imposibilidad de reconocerlos y denunciarlos a la justicia.

Habría entonces que leer un texto como Carne de perra como una crítica a la ideología patriarcal y a las formas en que desmantela la vida democrática en momentos de conflictos y crisis política, alterando todos los órdenes sociales, y en particular en lo que se refiere al régimen de género - o sea su fundamento- $\mathrm{y}$ a las identidades femeninas y masculinas, ya que la violencia sexualizada aparece como un arma de fuerza y dominio.

Carne de perra es un texto inédito en la producción chilena actual porque pone de presente la óptica de género en la representación de la experiencia del secuestro por motivos políticos, así como la subjetividad femenina de una prisionera política transformada en esclava sexual y colaboradora de un torturador violento y sádico, lo que da origen a lo que Carole Sheffield denomina "terrorismo sexual". Según Sheffield el derecho masculino de controlar el cuerpo femenino - su autonomía sexual y reproducción- es el fundamento del patriarcado. La violencia y su corolario, el terror, sirven para aterrorizar a las mujeres y mantener la definición patriarcal de su lugar como mujer (111). La confesión televisiva de un torturador sádico como Osvaldo Romo (El Guatón Romo) evidencia precisamente esta ideología patriarcal y el uso de la tortura y la violencia para quienes eran vistas como "más malvadas" que los hombres. Las mujeres se habían involucrado en política sin pensar en sus familias ni sus hijos según el exagente. Como ejemplo paradigmático de la mujer que ha abandonado su lugar tradicional, Romo cita a la activista y documentalista Carmen Castillo, quien estando embarazada estaba "dando problemas" (citado en Payne 115). Este eufemismo esconde la misoginia de los agentes del estado, quienes justifican sus delitos y su violencia sexualizada sobre las exmilitantes, haciendo uso de un discurso patriarcal y heteronormativo de los géneros dentro del marco del militarismo terrorista.

La escritora Fátima Sime revela la sexualización de la agresión que estructura la relación de dominio entre María Rosa y su torturador, desmantelando el mito mediático del síndrome de Estocolmo o lo que se ha llamado el amor de una víctima por su perpetrador. Entender la dinámica entre víctima y torturador mediante lo que este síndrome implica minimiza severamente, a mi parecer, el estado de dependencia e infantilismo al que el encarcelamiento y el dominio reducen a la secuestrada y torturada, clausurando cualquier posibilidad de libre consentimiento en sus acciones. El 
acto de agresión y posesión que implica la violación sexual como método de tortura debe ser entendido dentro de un continuum de violencia contra la mujer, es decir, una serie de eventos que están unidos por un carácter común (Sheffield 115). Sheffield sostiene que el silencio y la pasividad de las mujeres frente a la posibilidad de denunciar a los perpetradores y, habría que agregar, de que se reconozcan los asaltos sexuales como crímenes, están íntimamente ligados al miedo y a la socialización sexual que enseña a las mujeres que ellas son responsables del comportamiento sexual masculino. Por su parte, los hombres aprenden a desconfiar de las mujeres como parte de su educación y socialización de género. El silencio sobre la propia victimización y que los otros no crean lo que dicen las mujeres cuando denuncian los abusos sexuales, son resultado de una educación y de un sistema patriarcal de género, como subraya Sheffield (122). Por otro lado, Laura S. Brown explica el silencio de las mujeres a partir de la existencia de una dicotomía entre los ámbitos público y privado, que se extrapola al trauma y a la víctima en términos de género. Según Brown, la experiencia masculina del trauma normalmente es considerada pública, mientras que la experiencia traumática de las mujeres se ve en términos privados e incluso se asume como un problema personal, ya que el locus de su aflicción radica en relaciones interpersonales, en las que se instala el mito sexista de que la mujer es una víctima voluntaria de la violencia en este contexto (102). Esta visión tiene un gran impacto sobre cómo se entiende el trauma tanto en el área de la ley como en el de la psicología y sirve para sostener relaciones de poder en una sociedad heteropatriarcal. De hecho, para Brown hay una estrecha relación entre trauma y opresión, pues la angustia psíquica que experimentan las mujeres, las minorías y otros grupos marginados debido a la discriminación basada en el género, la clase, la raza y otras variables es síntoma de esta (105). Tanto Brown como MacKinnon coinciden en señalar que los abusos sexuales y la violación sexual son formas de discriminación y violencia ejercidas hacia las mujeres.

El Chile posdictadura al que ha regresado la protagonista de la novela Carne de perra como exiliada, se desenvuelve ajeno y sordo a la tortura física, sexual y psíquica a la que fue sometida por el antiguo agente de la represión, en un cuento de hadas perverso y macabro donde María Rosa era "su muñeca" o "su reina" (Sime 19). Este discurso, perteneciente a la retórica del amor

3 Este personaje recuerda al brigadier Miguel Krassnoff Martchenko, conocido torturador encargado de la represión del MIR como revelan los testimonios de Gladys Díaz. Era apodado "el duro" y "el caballo loco" de Villa Grimaldi. Estuvo implicado en 91 casos de detenidos 
cortés y a los cuentos infantiles, se da junto a la condición de "duro" que define al Príncipe en su trabajo clandestino de inteligencia y represión. Sus ataques de mal humor, violentos y repentinos, aterrorizan a la protagonistavíctima en un padecimiento sistemático al estar en sus manos durante los años de cautiverio. El agente del estado asume como propia la ideología de la Seguridad Nacional adoptada por la dictadura, expresada en la noción del "enemigo interno" y la guerra total contra el comunismo. Este aspecto del discurso literario expuesto por este siniestro y maquiavélico personaje incorpora la historia dictatorial y su hegemonía junto al impacto brutal que tuvo en la sociedad chilena a nivel político y social. Revela, además, "el control y la vigilancia de los servicios de seguridad sobre diversas instituciones estatales", desplegados durante la dictadura militar (Padilla), y que el relato trasluce en las conversaciones entre la prisionera y el torturador y en su proceso de adoctrinamiento. Para el Príncipe los métodos de represión y el terrorismo de estado son necesarios para la construcción de un nuevo Chile y el exterminio de "los indeseables", como lo expresa la siguiente cita paradigmáticamente: "Diga qué son los indeseables. Ella: Gente capaz de destruir el nuevo país que se está construyendo. No son muchos, pero son peligrosos. El, riéndose: Bien, muñeca, bien. Está aprendiendo" (Sime 97).

La memoria del pasado se gatilla por el reencuentro con su torturador, quien llega enfermo de gravedad a la UTI y a quien María Rosa debe atender en el presente narrativo. La escisión psíquica es análoga a la división entre un pasado violento y un presente desolador determinado por el aislamiento y el trauma. La vida de María Rosa en la capital transcurre entre el trabajo y un departamento casi vacío donde la acompañan diversos amantes que pasan una que otra noche con ella. La ausencia de una comunidad hace que la alienación y el trauma lleguen al clímax al encontrarse con su verdugo, quien en el presente del relato está físicamente débil y condenado por una enfermedad terminal. En el nuevo contexto posdictatorial, el extorturador está bajo la atención y vigilancia de quien fuera su víctima en una suerte de inversión radical de posiciones y poder. El exagente llega a la Posta precisamente porque

desaparecidos y fue acusado por delitos de lesa humanidad. Para más información ver http://centinela66.com/2011/11/16/miguel-krassnoff-martchenko-implicado-en-91-casosde-detenidos-desaparecidos-o-ejecutados-por-la-dina-policia-secreta-de-pinochet/ Cristián Montes, por su parte, afirma que se trataría de una representación literaria del cruel torturador del Estadio Nacional llamado Edwin Dimter Bianchi, alias el Príncipe, apodado así por ser alto, rubio y de ojos azules como en la novela (Montes). 
sabe que María Rosa trabaja ahí y quiere que cumpla su último deseo: morir a manos de ella antes que padecer el curso natural del cáncer.

En un contexto desigual y discriminatorio en términos de género y clase y durante un periodo dominado por la violencia política, la tortura se aplica de forma planificada para causar dolor físico o sicológico a través de agentes del estado. Como afirma Peel, el perpetrador siempre asegura que la tortura es necesaria para obtener información. Por su parte, los organismos de derechos humanos definen como tortura todo disciplinamiento, castigo o intimidación que se aplique para obtener una confesión — verdadera o falsa (11) - Según Peel, la tortura sexual es uno de los mecanismos que emplean los Estados autoritarios para demostrar su poder e impedir el disenso (11). Esta observación coincide con lo que dice la antropóloga Ximena Bunster en su importante artículo "Sobreviviendo más allá del miedo", en el que postula que el Estado se militariza y transforma en torturador, de manera literal y simbólica, en las dictaduras latinoamericanas. El autoritarismo patriarcal que lo define prescinde del Estado de derecho y gobierna mediante la represión y la impunidad. Bunster afirma que en el caso chileno las mujeres fueron disciplinadas severamente durante la dictadura, para obligarlas a integrarse al nuevo orden de género, en el cual su rol e identidad se limitaba a ser esposa/madre en la esfera privada. Junto a este reentrenamiento, las mujeres fueron definidas como inherentemente inferiores a los hombres, de quienes obtenían una identidad secundaria de madre, hermana, esposa y compañera. Todas aquellas que se resistieron a este régimen de género tradicional y discriminatorio eran "brutalizadas doblemente", mediante la tortura y la violencia sexual que se usó para controlarlas, intimidarlas y humillarlas con el fin de extirpar su identidad (Bunster 44-51).

La coerción, la manipulación y la agresión verbal, física y psicológica son algunas de las formas de acción que el victimario ejerce sobre la prisionera, a través de un método de tortura sexual que se dirige a diversos aspectos de la identidad y en particular a la identidad de género y la sexualidad. El objetivo de la violación sexual como método de castigo es humillar a la víctima e intimidar a los demás. Al ser una actividad planificada tiene consecuencias más graves y degradantes para quienes la padecen, como lo postulan Peel y el estudio de Carrera, pues se transforma en un fenómeno institucionalizado.

La experiencia traumática y su regreso a Santiago dejan a María Rosa desconectada emocionalmente, extremadamente vulnerable y víctima de ataques de pánico y de una serie de trastornos alimenticios similares a la anorexia. Este desorden se relaciona con mujeres sujetas al hambre por una 
suerte de temor hacia la comida, la cual se percibe como dañina para el organismo. Por esta razón, vomitar o experimentar hambre extrema son para la anoréxica formas de un ritual sacrificial donde el alimento y el cuerpo están íntimamente relacionados. Sentir hambre por el rechazo a comer, lleva a la anoréxica a un dominio imaginario fuera de lo natural cuyo objetivo es la purificación del cuerpo, tal como algunas prácticas religiosas lo hacen mediante el ayuno ritual. Esta abstención permite limpiar el cuerpo de impurezas como también tener transformaciones sustanciales en las etapas vitales y en la relación entre la vida y la muerte (Spignesi 17-21). La anorexia de María Rosa es una forma de controlar su propio cuerpo y vitalidad luego de los vejámenes sexuales sufridos a manos de su torturador, todos vinculados a la comida favorita de este. Poder, cuerpo y comida se entrelazan en la perversión del Príncipe y la sujeción de su prisionera. La vergüenza y la culpa que experimenta la protagonista en el contexto carcelario, se transfieren al cuerpo, visto como invadido, y a la comida que en vez de nutrir, destruye. Su nuevo cuerpo - raquítico y frágil- refleja la condena de lo orgánico y natural, en la que el alimento ha sido substituido por imágenes psíquicas, como afirma Angelyn Spignesi al referirse a este desorden psíquico/corporal (22). Esta transformación, sin embargo, puede leerse como una suerte de rebelión y resistencia a la condena que supone ser solo materia biológica en la cultura patriarcal y convertir el cuerpo femenino en forma discursiva con significación psíquica (22).

El asco a la comida y la dificultad para comer y alimentarse son algunas de las secuelas de la violencia sexual a la que fue sometida la protagonista de Carne de perra. De tal modo, el cuerpo aquí revela todo un repertorio de síntomas, memorias y flashbacks que la siguen atemorizando y que llevan a María Rosa a revivir las experiencias traumáticas del secuestro y la esclavitud sexual en la que vivió durante dos años, lo que la convierte en una desaparecida más para sus familiares.

Como Montes ha advertido, la novela de Sime se inscribe dentro de la narrativa postdictatorial que reflexiona y revisa el pasado y los efectos de la violencia política en el presente. La memoria y el trauma irrumpen e interrumpen la normalidad neoliberal de una sociedad que aún hoy no resuelve satisfactoriamente las cuentas pendientes con las víctimas de la dictadura y que solo ha logrado verdades a medias en materia de justicia y derechos humanos, impelida por la transacción entre mercado y democracia.

El relato representa la dependencia total que tiene María Rosa de su torturador, cuyo poder y fuerza agresiva la definen como su esclava sexual 
silenciosa, programáticamente entrenada con gritos, insultos, golpes y abusos para aceptar la voluntad de su amo y desmantelar su propia estructura psíquica e identitaria. De hecho cualquier palabra o pregunta equivocada de la prisionera al Príncipe es reprimida mediante el insulto y la humillación soez de forma inmediata y brutal. Seguir sus órdenes al pie de la letra es la norma que la mujer abusada debe acatar sumisa e incondicionalmente, ya que de lo contrario la agresión verbal, física y sexual surgen en el acto. De ser "su muñeca", María Rosa pasa en un instante a ser una "mierda" $(32,54)$, una "concha de tu madre" (51), una "puta reputa" (55), una "puta de mierda", (55), una "imbécil" (64) o una "perra de mierda" (76), entre otros apelativos que la deshumanizan, y que subrayan que el Príncipe es un amo violento, cambiante y difícil de complacer. De tal modo, el abuso y la denigración contribuyen al evidente debilitamiento físico y psíquico de la protagonista, quien cada vez está más temerosa y es más dependiente del Príncipe en una situación determinada por un doble vínculo hacia quien la domina y maltrata. La ambigüedad y ambivalencia que caracterizan el comportamiento y el discurso del torturador, confunden a María Rosa, pues haga lo que haga no tiene manera de entender la realidad creada por el sadismo y dominio sexual que rige el Príncipe. ${ }^{4}$

Más aún, su destino depende del torturador, pues él decide diariamente que siga con vida. En este mundo de dominio total, el sexo juega un papel fundamental y adquiere un doble significado también, ya que se torna elemento de sobrevivencia, por un lado, y de castigo, por otro, en un juego perverso que apresa a María Rosa. Según MacKinnon el sexo se convierte en moneda de cambio y en herramienta de deshumanización dentro de una economía sexual corrupta y de fuerza, tal como les ocurrió a las mujeres judías prisioneras durante el Holocausto (MacKinnon 324). La humillación y deshumanización de estas mujeres era claramente sexual en actos explícitos de sadismo sexual, en los que la tortura también se daba en el sexo, porque la infligían los alemanes, quienes eran supuestamente superiores a los judíos,

4 Para un análisis más profundo sobre la noción del doble vínculo de Gregory Bateson y su aplicación a casos de mujeres sobrevivientes, ver mi artículo "Memoria y traición femenina en la ficción y el testimonio (La doble vida de Arturo Fontaine, El fin de la historia de Liliana Heker y testimonios de sobrevivientes)" en Kamchatka: Revista de Análisis Cultural de la Universidad de Valencia. También puede consultarse mi trabajo "Testimonio y memoria en Argentina y Chile: la sobreviviente frente a los Derechos Humanos", de pronta aparición en Otras Modernidades: Rivista di Studi Letterari e Culturali, de la Universidad de Milán. 
sus inferiores (324-325). La violación, comenta MacKinnon tanto en el caso alemán como en el de Ruanda, es la regla y no la excepción (325). Lo mismo podría decirse del terrorismo de estado en Chile y otros países del cono sur, donde se utilizó la violencia sexual y de género como tortura, un hecho que hoy en día es reconocido en las cortes internacionales como genocidio.

De hecho, en la representación del abuso sexual en la novela de Sime, la penetración psíquica, física y sexual es literal y simbólica mediante los ritos sádicos que organiza el torturador para introducirse en su víctima con toda suerte de productos alimenticios. El hecho de que no pueda realizar la penetración vaginal funciona aquí para exaltar las aberraciones a las que somete a María Rosa, quien, sumida cada vez más en la pérdida identitaria, es casi incapaz de hablar. Su condición de mujer vejada sexualmente la torna objeto consumible en un escenario donde la perversión y la pornografía se citan entre las órdenes y el voyerismo de su amo. La eclosión del contrato sexual en esta novela testifica también el fracaso del contrato social en una sociedad dominada por el neoliberalismo y el consumismo que aún no se ha hecho cargo de relatos y testimonios de sobrevivencia marcados por el abuso sexual de mujeres que padecieron circunstancias de tortura análogas a las de la novela.

Luego de ser trasladada de uno de los pisos ("El Cielo") de la casa de tortura clandestina donde María Rosa fue detenida y torturada por agentes, el Príncipe la encierra en un baño. Sin conciencia y casi al borde de la muerte, el torturador se aboca a la tarea de revivirla y reeducarla. Al estar aislada y encerrada después de haber sufrido quemaduras en la cara producto de la tortura y cuyas costras le saca el Príncipe con un cuchillo para divertirse, se establece una relación sadomasoquista regida por el poder. El torturador la obliga a comer, a vestirse y a someterse a toda clase de torturas sexuales. La impotencia sexual se compensa en los diversos ritos y la excitación que le produce al Príncipe tener poder irrestricto sobre una mujer victimizada a voluntad. Vestirla, calzarla, alimentarla, poseerla sexualmente, regalarle pasteles y champán y disponer de ella como un objeto, caracterizan el comportamiento del torturador, convertido en amo omnipotente. De este modo, va adueñándose y vaciando la identidad de María Rosa, quien es víctima constante del temor al dolor y a la muerte, dos posibilidades siempre reales que las amenazas y la agresividad de su captor le recuerdan. El Príncipe pasa drástica y violentamente de la gentileza a la ira, del elogio al insulto y del beso al golpe. Los cambios de ánimo y de estados mentales, hacen de él un torturador temible que disfruta infligiendo dolor y anulando al otro. En 
el poder absoluto sobre María Rosa transformada en su esclava, encuentra confirmación sobre la idealización de la mujer convertida en reina y la brutalidad que la animaliza, insulta o agrede física y sexualmente. Además de la afirmación de la masculinidad que tradicionalmente implica la violación sexual, en el contexto del genocidio sexual del que participa el imaginario de este relato, la supremacía del grupo superior - los militares y sus agentes- es la prueba de que ellos son los "dueños", porque son "mejores" y los que "poseen" a sus víctimas, al decir de MacKinnon (328). Dentro de esta lógica, el Príncipe posee y abandona a la protagonista, disponiendo de ella según su voluntad y deseo.

Ya que la penetración sexual no le es posible la substituye mediante la inserción vaginal de toda clase de alimentos, frutas y pasteles de crema que luego come y succiona del cuerpo de su prisionera en una especie de festín sexual que borra los límites del cuerpo y los objetos. María Rosa debe seguir todas sus instrucciones para realizar actos sexuales que lo excitan. Primero debe desnudarse y abrirse de piernas en la cama o en el suelo o bailar desnuda sobre una mesa para excitar al torturador, quien la cubre bien de champán, ostras, higos u otros alimentos, en una igualación entre la mujer y la comida o bebida (recorriendo el espectro de productos de la comida diaria hasta aquellos más costosos). El miedo a la castración es evidente en estas diversas escenas sexuales, en las que la comida se vuelve un fetiche que substituye al pene y a la penetración de la cual el Príncipe es incapaz. Tal como subraya Freud, el horror a la castración hace que el fetiche sea una especie de victoria y protección. En este sentido podemos ver que la perversión del Príncipe es un tipo de neurosis que acepta parte de la realidad sin perderse completamente en su propia fantasía. La idea de la realidad en el fetichista está presente y ausente y se divide entre diversas corrientes mentales.

El padecimiento físico de la prisionera también es esencial en los juegos sexuales que impone el captor. Las posiciones y roles se repiten y él es quien ejerce la fuerza sobre el cuerpo pasivo de la víctima. La violencia sexual se practica en estas condiciones sin otros límites que la voluntad del victimario, cuya megalomanía es análoga al orden dictatorial y a la fuerza brutal que ejerce en la construcción de un nuevo Chile para el que secretamente enlista a su prisionera después de dos años de secuestro y victimización.

Como mujer abusada, María Rosa se convierte en la compañera material de todas las fantasías masculinas masturbatorias del captor, al decir de Slavoj Zizek. El relato da cuenta de la fantasía absoluta que organiza la economía sexual fálica sobre el sacrificio femenino. La protagonista al ser 
violada sistemáticamente se entrega sumisamente para satisfacer a su cruel y veleidoso amo. La captura y el sometimiento sistemático, primero en la cárcel clandestina, y luego en el departamento arrendado por el Príncipe, donde termina instalándola sola, tienen como resultado la renuncia a sí misma. La mujer se transforma en un objeto más dentro de la perversión del torturador y toda su existencia se vuelca hacia él. En este espacio cerrado y violento, él la somete y consume, recurriendo al miedo y al castigo corporal y psíquico día tras día en el aislamiento. A pesar de pasar la mayor parte del día sola, María Rosa no intenta escapar ni pedir auxilio. Su voluntad e identidad han sido desmanteladas y vive orgánicamente a través de su torturador. Como afirma Cristián Montes, "Las invasiones convierten al cuerpo, a la voz y a las emociones de la víctima en instrumentos de poder disponibles para ser usados en su contra" (72), por lo que no puede sustraerse a la sujeción.

La colaboración de María Rosa con el plan de asesinato del Príncipe nace en este contexto y condiciones, a cambio de la sobrevivencia. María Rosa es transportada a un hospital para envenenar a un político de oposición, importante, evocando el asesinato del presidente Eduardo Frei en 1982 en condiciones similares, en una clínica de Santiago a la que había ingresado por una hernia y donde murió envenenado. ${ }^{5}$

La complicidad del Estado dictatorial es evidente a través de las garantías de impunidad y la lógica de la carta blanca de sus agentes y funcionarios públicos, quienes eran libres de imponer un estilo particular al poder re-

5 Wikileaks filtró documentos de la Embajada de Estados Unidos en los que aparecía información sobre la autopsia que realizaron unos médicos de la Universidad Católica sin autorización familiar y en la que se sacó el veneno para luego embalsamar el cuerpo. Las investigaciones judiciales del 2005 revelaron los nexos entre la planta de médicos y enfermeras de la Clínica Santa María y la CNI. Entre las enfermeras, figura Eliana Borumburu, enfermera jefa de las clínicas de la DINA, que tenía relaciones familiares y conexiones con funcionarios del Hospital de la Universidad Católica, precisamente de donde salieron los médicos que realizaron la autopsia de Frei. El operativo de María Rosa en la clínica tiene claras similitudes con los de Eliana Borumburu. En el 2009 se dicta la resolución judicial donde se establece que la muerte de Frei se produjo por la introducción de productos farmacológicos no autorizados que deterioraron su sistema inmunológico. Cuatro médicos y dos personas más fueron imputados como autores, cómplices y encubridores del primer crimen de magnicidio en la historia nacional. En el 2014, mediante las declaraciones de un exagente de la represión, se supo que el fallecimiento de Frei se presentó luego de que le pusieran compresas infectadas en la herida producida por la operación de la hernia. Este, justamente, es el procedimiento que aprende y aplica María Rosa siguiendo las órdenes de su torturador. 
presivo en las condiciones ilegales en que lo ejercían, tal como lo hace el Príncipe en este texto.

El relato, además de denunciar los abusos de los torturadores y exagentes del Estado militar, revela las perniciosas formas de dependencia emocional que las víctimas de violencia sexual y de género pueden desarrollar con sus abusadores producto del arrasamiento subjetivo. En la representación del pasado y del presente de María Rosa como sobreviviente de tortura, la novela también indaga por la violencia hacia la mujer como un problema social y político invisibilizado por el silencio (de la víctima y de la sociedad).

La forma en que María Rosa resuelve su pasado, decidiendo cegar la vida de su antiguo verdugo, abre el debate hacia los límites del sistema legal y la justicia en Chile. Después de repasar las diversas confesiones de ex torturadores agentes del Estado represor y los testimonios de las sobrevivientes, junto a las representaciones literarias en Chile en la última década, Carne de perra es tal vez el relato más osado en su concepción de la justicia como retribución, concebida como única alternativa para la mujer prisionera, torturada y abusada sexualmente durante la dictadura, pues el propio sistema legal se la niega por su propia estructura patriarcal. El desenlace de Carne de perra podría leerse también como una eutanasia o muerte asistida dada la condición terminal del violador. Sin embargo, la ambigüedad del texto admite interpretar el acto final de la enfermera como una forma de justicia que solo ella puede realizar en ausencia de una ley de género que reconozca y legisle sobre los delitos específicamente perpetrados contra las mujeres. En definitiva, este es también un comentario sobre el estado de la justicia y la ley en Chile en materia de derechos humanos y, en particular, sobre los derechos humanos de las mujeres como sujetos ciudadanos con autonomía sexual y libertad. La invisibilización de estos crímenes ha silenciado memorias sexuadas, al decir de Ana Forcinito, que deben no solo reconocerse social y políticamente sino atenderse legalmente ("Las batallas de la memoria"). La ausencia de una perspectiva de género frente a la agresión sexualizada perpetrada por los agentes represores, ha tenido un impacto en las formas en que se registran estos crímenes como también en el reconocimiento de lo que realmente significaron dentro de la política genocida de la dictadura. En este sentido, la novela Carne de perra coloca en primer plano la memoria traumática de la sobreviviente de tortura sexual y de género en el contexto de la historia del terrorismo de estado en Chile, haciendo una relectura de ese pasado aún sin resolver y de las formas de la violencia perpetradas contra la mujer. 


\section{Obras citadas}

Brown, Laura S. "Not Outside the Range. One Feminist Perspective on Psychic Trauma". Trauma. Explorations in Memory. Ed. Cathy Caruth. Baltimore: The John Hopkins UP, 1995 100-112. Impreso.

Bunster, Ximena. "Sobreviviendo más allá del miedo". La mujer ausente; derechos humanos en el mundo. Eds. Ximena Bunster, Cynthia Enloe y Regina Rodríguez. Santiago de Chile: ISIS, 1996. 45-63. Impreso.

Carrera, Carolina. "Secrets Revealed. Women Victims of Sexual Violence as Torture during Chile's Era of Political Repression 1973-1990". The Free Library. Web. 24 de marzo de 2016.

Cassino, Miranda. "Género y genocidio. Aportes a la reflexión sobre el terrorismo de Estado". Género y poder. Violencias de género en contextos de represión política y conflictos armados. Ed. María Sonderéguer. Bernal: Universidad Nacional de Quilmes, 269-288. Impreso.

Forcinito, Ana. "Las batallas de la memoria: violencia sexual y derechos humanos en Argentina". Letras Femeninas (Summer 2013): 93-111. Impreso.

Freud, Sigmund. "Freud on Fetichism". Live fournal. Web. 26 de febrero de 2016.

Fríes, Lorena, Victoria Hurtado y Ximena Zabala. "El proceso de justicia transicional y el derecho a la reparación por violencia sexual como tortura en Chile". Género y poder. Violencias de género en contextos de represión política y conflictos armados. Ed. María Sonderéguer. Bernal: Universidad Nacional de Quilmes, 83-132. Impreso.

Llanos, Bernardita. "Memoria y traición femenina en la ficción y el testimonio (La doble vida de Arturo Fontaine, El fin de la historia de Liliana Heker y testimonios de sobrevivientes)". Kamchatka: Revista de Análisis Cultural s.n. (2015): 853-863. Impreso.

Llanos, Bernardita. "Testimonio y memoria en Argentina y Chile: la sobreviviente frente a los Derechos Humanos". Otras Modernidades: Rivista di Studi Letterari e Culturali (manuscrito aceptado para publicación).

MacKinnon, Catharine. "Genocide's Sexuality". Political Exclusion and Domination. Eds. Melissa S. Williams y Stephen Macedo. Nueva York y Londres: New York University Press, 2005. 313-356. Impreso.

Mendoza, Annie. Rewriting The Nation: Novels by Women on Violence in Colombia. Tempe: AILCFH, 2015. Impreso.

Montes, Cristián. "Carne de perra, de Fátima Sime: la persistencia de lo urgente". Iberoamericana 11.44 (2011): 63-78. Impreso.

Padilla Ballesteros, Elías. La memoria y el olvido. Detenidos desaparecidos en Chile. Archivo Chile. Web. 24 de marzo de 2016. 
Pateman, Carol. The Sexual Contract. Palo Alto: Stanford UP, 1988. Impreso.

Paynem Leigh. Testimonios perturbadores. Bogotá:

Universidad de los Andes, 2009. Impreso.

Peel, Michael, ed. Rape as a Method of Torture. Freedom from Torture. Web. 26 de febrero de 2016.

Pratt, Mary Louise. "Tres incendios y dos mujeres extraviadas: el imaginario novelístico frente al nuevo contrato social". Espacio urbano, comunicación y violencia en América Latina. Ed. Mabel Moraña. Pittsburgh, PA: Instituto Internacional de Literatura Iberoamericana, 2002. 91-105. Impreso.

Sheffield, Carole. "Sexual Terrorism". Gender Violence. Interdisciplinary Perspectives. O'Toole Schiffman y Kiter Edwards. Nueva York y Londres: New York University Press, 2000. 111-130. Impreso.

Sime, Fátima. Carne de perra. Santiago: LOM, 2009. Impreso.

Spignesi, Angelyn. Starving Women. A Psychology of Anorexia Nervosa.

Dallas, Texas: Spring Publications, Inc., 1983. Impreso.

Zizek, Slavoj. "Femininity between Goodness and Act". The

Synthome 14 (2013). Web. 26 de febrero de 2016. 